\title{
'A very individual thing': Findings on drug therapy in psychiatry from the perspective of Australian consumers
}

\author{
Pam McGrath $^{1}$, Michael Bouwman ${ }^{1}$ and Vaidyanathan Kalyanasundaram ${ }^{2}$
}

1. International Program of Psycho-Social Health Research, Central Queensland University, Australia 2. Department of Psychiatry, University of Queensland, and Bayside Health Services District, Redland Hospital, Cleveland, Queensland, Australia

\begin{abstract}
Ten participants were interviewed as to their experiences which led to their recovery from mental illness. A variety of both positive and negative experiences relating to the use and misuse of drug therapy reported by these consumers highlights the much personalised nature of recovery. In particular, the timeliness of the drug therapy, the duration, type and dosage of prescribed drugs, and even whether prescribed drugs were used at all, were all factors reported to impact on recovery. The findings highlight many negative aspects of the drug imperative within the Australian psychiatric system. Participants indicated that in their experience the mainstay of psychiatry is the administration of drugs which are given often without counselling, with little information and scant support to either the patient or their family. Individual resistance to drug therapy is seen as experimental and not easily tolerated within the mental health system: a system described as disempowering, offering scant therapeutic choices and not respecting individual difference. A minority of participants do value the contribution that drug therapies can make to control the worst aspects of their mental illness. Also, drug treatment is seen as particularly important during a psychotic episode. The findings contrast the use of drug therapy as a means of 'risk management' with a consumer oriented self-driven recovery model. To explore therapeutic strategies other than drug treatments, the consumer needs to be highly motivated, mindful of the family consequences, and have the trust and support of a sympathetic psychiatrist.
\end{abstract}

\section{Keywords}

recovery, drugs, medication, consumers, service delivery, qualitative research

\section{Introduction}

The possibility of recovery from mental illness as opposed to the mere management of mental illness has become accepted as a widespread goal in modern psychiatry (Anderson, Oades \& Caputi, 2003; Anthony, Rogers \& Farkas, 2003; Bishop, 2001; Jacobson \& Curtis, 2000). In Australia, the notion of recovery is now enshrined in Commonwealth government documents as evidenced by the statement from the (third) National Mental Health Plan 2003 2008:

Recovery is both a process and an outcome and is essential for promoting hope, well-being, and a valued sense of self-determination for people with mental illness. A recovery orientation emphasises the development of new meaning and purpose for consumers and the ability to pursue personal goals. Mental health service providers should operate within a framework that supports recovery. (Australian Health Ministers, 2003, p. 5).
Contact:

Citation:

Published by:
Dr Pam McGrath, Director, International Program of Psycho-Social Health Research (IPP-SHR), Central Queensland University, Kenmore, Queensland, Australia. pam_mcgrath@bigpond.com

McGrath, P., Bouwman, M., \& Kalyanasundaram, V. (2007). 'A very individual thing': Findings on drug therapy in psychiatry from the perspective of Australian consumers. Australian e-Journal for the Advancement of Mental Health, 6(3), www.auseinet.com/journal/vol6iss3/mcgrath.pdf

Australian Network for Promotion, Prevention and Early Intervention for Mental Health (Auseinet) www.auseinet.com/journal

Received 28 August 2007; Revised 25 October 2007; Accepted 25 October 2007 
In addition, the concept of recovery itself has undergone an evolution away from the notion of a restoration to a 'normal' state, towards a transformative process in which a new sense of self emerges (Deegan, 1996). Dating back to the late 1980s, this change in understanding from restoration to transformation, has largely been driven from consumer insights on the experience of recovery. Indeed, personal reflections from individuals coping with the challenge of mental illness have been at the forefront of the conceptualisation and instigation of the recovery movement (Deegan, 1988, 2003). Qualitative research methodologies have also been instrumental in ensuring that the voice of the consumer is heard in a way that contributes to changes in conceptual understanding of recovery in relation to mental health care practice (Mancini, Hardiman \& Lawson, 2005; Ramon, Healy \& Renouf, 2007).

While acknowledging the evolution of the concept of mental illness as a move from a chronic disorder to a more optimistic position incorporating the notion of recovery, recent studies are mostly silent on the significant impact of pharmacotherapy in recovery (Hutchinson, Skrinar \& Cross, 1999; Kirkpatrick, Landeen, Woodside \& Byrne, 2001; Pejlert, Asplund \& Norberg, 1999; Ramon et al., 2007; Russlinova 1999; Tse \& Walsh, 2001; Young \& Ensing, 1999). As Happell, Manias \& Roper (2004) point out, the literature largely ignores the views and experiences of consumers of mental health services in relation to medication. In order to address the gap in exploring the benefits or otherwise of drug use, this article reports research findings on the role and significance of pharmacotherapy from a consumer perspective within this emerging and evolving framework. The insights discussed in the article are gathered from a qualitative research project exploring factors that contribute to recovery in mental illness from the consumers' perspective.

\section{The research}

The findings are from a sub-project of a larger research project funded by a Central Queensland University Merit Grant that followed up clients from the Project 300, a mental health, disability and accommodation package established by Queensland Health in 1995 to assist 300 clients with psychiatric disabilities. The aim of the subproject is to explore, through qualitative methodology, the factors that contribute to recovery from mental illness. This research involves interviews with individuals chosen because they are articulate about their recovery from mental illness. Full ethical clearance was obtained for the interviews from the university ethics committee. The interviewees were provided with a written project description, informed verbally of their rights as a research participant and signed a written consent form at the point of agreeing to participate.

\section{Methodology}

The ten participants for this arm of the study represent a purposive sample of individuals who were chosen on three criteria: first, they had an official DSM-IV psychiatric diagnosis for a mental illness; second, they were able to demonstrate recovery from that illness; and, third, they were articulate and sufficiently motivated to express in words the experience of recovery. Participants documented their own criteria for recovery which included evidence of remaining symptom free, of maintaining a support and friendship network, of engaging successfully in meaningful occupation or study, and of investing energy as a volunteer into assisting others coping with a mental illness. Participants were enrolled through the snowballing techniques of networking within the mental health consumer network. The intent behind such a purposive sample was to provide an opportunity for articulate mental health consumers to provide leadership in the way of providing insights on recovery for those less able to express themselves.

Data were collected through a non-directive Rogerian interview that proceeded at the interviewee's pace, with constant checking by the interviewer that the material dealt with remained within the comfort zone of the participant. The interviews started with the question, 'Could you talk about your recovery process, taking as much time as you need and talking about issues that you think are important?' At times the interviewer asked for clarification of statements and also summarised the progress of ideas to affirm that the interviewer understood the ideas expressed correctly. The interviewer did not impose a 
structure on the interviews but rather engaged with the flow of the discussion in the direction established by the interviewee. In relation to the focus of this article, the use of medications, all interviewees posited the issue for discussion.

The interviews lasted for approximately two hours. They were audio-recorded and transcribed verbatim. The language texts were then entered into the NUD*IST computer program and analysed thematically. A phenomenological approach was taken to the recording and analysis of the data. The aim of phenomenology is to describe particular phenomena, or the appearance of things, as lived experience (Streubert \& Carpenter, 1995). The process is inductive and descriptive and seeks to record experiences from the viewpoint of the individual who had them without imposing a specific theoretical or conceptual framework on the study prior to collecting data (Polit \& Hungler, 1995). All of the participants' comments were coded into free nodes (a technical term for the categories created on the QSR NUD*IST N5 program to store statements that relate to a similar topic), which were then organised under thematic headings. There were one hundred and forty-one $(n=141)$ free nodes created from the interviews, of which the data from the seventeen $(n=17)$ free nodes on medication and recovery are presented here. The findings on other individual topics are being published in separate articles, with a repeat here of the methodology section to confirm the origin of the data from the one study (McGrath \& Jarrett, 2004).

\section{Findings}

\section{Automatic use of drugs}

A strong common theme reported by all participants is the idea that there is an automatic use of drugs within the psychiatric system, creating immediacy and pressure for the consumer to embrace a drug based response to their illness. As the following statement indicates, doctors and psychiatrists were described as having a therapeutic imperative to use drugs:

I understood that there's this process, he needed to, because he was a doctor, to go through, and try medication.

Participants spoke of the process of visiting the psychiatrist, receiving a diagnosis and little other information, and then being put straight onto drug therapy.

My family wasn't given a diagnosis. Not given any information, and they'd say, 'Alright, we're going to increase your medication to this,' and leave it at that.

Even when a consumer is sufficiently empowered to ask for non-drug therapy this is not necessarily provided by the system. One participant described this situation as follows:

I said, 'I want therapy.' I have not talked about these things that have happened to me as a child, and I need to. He said, 'No we have to medicate you first. I will not do therapy until you are stable.' And I said, 'I don't think I can be stable until I've done therapy.'

Counselling is not readily available even to back up drug therapies:

Counselling - there was [none]. My doctor who put me on it [drug name] went overseas for six weeks, and I couldn't even ring him.

Participants spoke of the oppression such a drug imperative created and described the hospital psychiatric system as disempowering and prisonlike, 'The hospital's another big, big terrible place. It's so run like a jail system.'

Suggestions were made about the need to move away from the drug centred approach to a community support approach.

\section{Individual reactions}

Participants emphasised that this blanket and uniform approach to prioritising drug based therapies does not take individual variation into account. One participant succinctly summed up the situation with regards to best therapy: 'I just find that it's a very individual thing.'

\section{For some, drugs are part of the solution}

Because so many of the participants had very negative experiences with drug regimes, it is important to state clearly that a minority of participants did value the contribution that drug therapies made to controlling the worst aspects of their mental illness. As one participant explains:

I'm on the same medication now, and I'm very lucky that I just... I have basically lithium, but that does help me a lot - I realise it does help me a lot, I've never gone off medication.

However, even for these patients drugs were seen as only part of the solution: 
Oh, absolutely, it's not the whole solution, but it's a part of the solution. I'm still on a very mild dose of lithium carbonate, and I religiously stick with that, and I openly share it with consumers to help them to accept the fact that it does help to stabilise. But that's, as I say to them, 'It's a safety net to me.'

\section{Difficult side effects}

Only one participant indicated a lack of significant difficulties with the side effects of drug therapy. Most participants spoke at length about the difficulties they experienced in relation to the side effects of drugs. As there were a multiplicity of drugs referred to for varied psychiatric conditions, this discussion will not attempt to provide a detailed clinical account on side effects. Rather, the emphasis will be on providing a diversity of insights about the challenge of dealing with side effects from the consumer's perspective. Table 1 outlines a list of the most difficult side effects in lay language, accompanied by a description of the experience from the consumer's perspective.

The specific description of side effects was also accompanied by more general statements of a sense of misery when on the drugs, examples of which are:

... how horrific I felt.

... there were huge changes.

I did not like the side effects.

Table 1. Lay description of side effects with participants' accompanying experience

\begin{tabular}{|c|c|}
\hline Difficult side effect & Description of experience \\
\hline Emotional numbness & The drugs make you quite numb to everything. \\
\hline A sense of disassociation & $\begin{array}{l}\text { I just felt like I was on the outside. } \\
\text { I was in limbo. }\end{array}$ \\
\hline Agitation & $\begin{array}{l}\text { That was pretty hard to deal with. I remember smacking quite a few doors not long after I come } \\
\text { out of hospital. }\end{array}$ \\
\hline Restlessness & I heard it was something like induced Parkinson's (Disease) and I had a lot of that. \\
\hline Weight gain & I put on 18 kilos ... I didn't quite know how to deal with how I felt about these pills. \\
\hline Thirstiness & I was thirsty all the time and I did not feel like myself. \\
\hline Anaphylactic shock & I went into anaphylactic shock in the end. \\
\hline Itchiness & I would itch and there was various other things. \\
\hline Hair loss & $\begin{array}{l}\text {... for six months, and I do believe that it really affected my health. My hair fell out, and all of that } \\
\text { sort of thing. }\end{array}$ \\
\hline Heart condition & $\begin{array}{l}\text { And I believe to this day that the weakness in my heart that caused me to have ventricular } \\
\text { tachycardia was because I was put on these heavy drugs. }\end{array}$ \\
\hline Social isolation & $\begin{array}{l}\text { I hibernated in the house for about the first three and a half years and slept, and just functioned ... } \\
\text { basically, as a robot. }\end{array}$ \\
\hline Listlessness & Just no emotion, no sense of personal hygiene, or just existing. \\
\hline Over sedation & I was just over sedated. You wouldn't get 'Boo' out of me. \\
\hline Lack of motivation & $\begin{array}{l}\text { I'd go into hospital, they would over sedate me again, and l'd find myself not being able to work, } \\
\text { not being able to apply myself, and lapsing back into the lounge chair smoking cigarettes and } \\
\text { drinking coffee. And that's my existence. You don't have enough motivation to have a shower in } \\
\text { the morning. }\end{array}$ \\
\hline Tooth decay & All my teeth were rotted out from over dosing. \\
\hline Drowsiness & I couldn't wake up. \\
\hline Memory loss & $\begin{array}{l}\text {... I went along for the first three months when I was over sedated - I didn't take a thing in, } \\
\text { because I couldn't think. My short term memory and my long term memory are lost. I used to have } \\
\text { a great memory ... Whether that's the drugs or the illness I don't know, but I think it'd be the } \\
\text { combination. }\end{array}$ \\
\hline Loss of sense of humour & $\begin{array}{l}\text { I used to have a sense of humour, but I've lost that - It's trapped somewhere, I don't know. } \\
\text { Haven't laughed in years. }\end{array}$ \\
\hline Diarrhoea & $\begin{array}{l}\text { I get diarrhoea with it. And it's not pleasant to wake up to that every morning, and that's been the } \\
\text { case for two years now. }\end{array}$ \\
\hline Addiction & I became a valium addict. \\
\hline
\end{tabular}


The drugs were described as affecting key emotions with which to deal with life, as one participant reported:

You can't laugh, you can't smile, you see a comedy or a tear jerker, you don't display any emotion - they're very strong drugs.

Special problems are reported to occur with slow release drugs.

But see ... the problem is that a lot of the time you don't know, because these slow release drugs are a slow release, [they] creep up on you and you're not aware of the over sedation until someone says, 'Oh, you're not talking much today?'

There was a sense in which the drug made the person's condition feel worse. 'No, the mood stabilisers don't help ... they made it worse.'

For some, the drugs contributed to a sense of depression, 'I was very deeply, darkly, depressed by what that [drug name] actually did'; for others, a zombie-like feeling, 'I was a zombie - I felt zombiefied most of the time. My arms and legs used to get in the way.'

Mostly the descriptions of the experience of drug side effects were in negative terms such as 'devastating for you' or 'like driving me batty.' Some participants described their experience with side effects with anger,

When I did come out of the state where I wasn't over sedated, I got very angry at the system for locking me away.

and with a deep sense of unfairness,

Because the thing is, why was I allowed to suffer for three and a half years ... being over sedated? I mean, it seems so unfair ... that they would do this to someone.

The important issue is that while on the drugs the participants felt unprepared to deal with some of the side effects and were not given assistance. As one participant stated:

Some of the side effects ... like and you know ... they don't do anything about it.

\section{Lack of information to deal with side effects}

There was a strong common theme that participants were not given sufficient information or supportive discussion to understand and know how to deal with their side effects:

... [name of drug], which was highly reputed to do that, but they don't tell you this.
He still didn't tell me what I was on or why I was on anything, and I started to get side effects.

...started to get all the shaking and the restlessness, and I didn't know what was happening, and I remember walking up to a nurse and saying, 'You know, I'm agitated'. And she said, 'Oh, it's not the medication, and walked away from me.

As the following statements indicate, some just suffered in silence, 'I kind of just had to battle with it, without any knowledge of what was going on', while others sought answers:

Well, it's been pretty negative from my perspective, in the first few years, trying to get answers. My family couldn't get answers to what was going on.

The important point is that the participants indicated that they were in a disempowered position, unable to advocate for answers to the problems of side effects, 'I was in no state to intervene on my own behalf, 'cause I was too over sedated, too unwell.'

\section{Need to change or experiment with different drugs}

Participants reported the importance of being able to explore with their psychiatrist the possibility of either changing the dose or the drug used during therapy.

Medication is another thing. You know, you talk it over with your doctor; 'Oh I don't like this, it makes me feel terrible', 'Oh, we'll get you on this' or 'That one makes me feel stupid.'

The point is that where a participant is committed to a drug therapy such commitment is accompanied by a desire to ensure the drug(s) and drug doses are appropriate.

I realise that the doctors and nurses are all there for your health, and to accept the help that you're getting, always take your medication ... you might say to him, 'Look it affects me at work' or something like that. They might put you on a lower dose, or what they might do is change you [to] a different medication that might be better suited to you.

It was reported as easier to engage in such dialogues with the medical profession where the person is known and is respected as rational.

\section{Desire to get off drugs}

Some participants spoke about their desire to cease drug taking. Some made this happen with the support of their psychiatrist: 
I had to be on the drugs for at least six months, and so I just started to count down and basically, I said to him, 'You know, come on, I want to get off these drugs,' and so he let me.

As described in detail elsewhere from further findings from the study (McGrath \& Jarrett, 2004), a significant part of one participant's journey to recovery was finding a sympathetic psychiatrist who allowed and supported attempts to experiment with going on and off different drugs. This support allowed the person to see what was most effective and what role drugs would play in the recovery process. Other participants saw going off drugs as a goal for the future.

Yes... and I believe some day I'll probably come off medication. And you know, when that happens, it happens. At the moment, it keeps those things at bay while I deal with life, I guess.

The process of ceasing drug therapy was seen as experimental and going against standard practice; a process not necessarily supported by health professionals.

\section{Psychosis need drugs}

The one time when participants agreed that drugs were needed was when the person was in a state of psychosis.

I guess when you're deep in a psychosis, there's not a lot you can do. You have to come to a bit of an insight that you're unwell. Then you have to take the tablets that are given to you.

An important caveat to this insight is that even though participants recorded the need for drug therapy during psychotic phases, they still saw the psychotic breakdown as related to emotional stress.

... I was trying to figure out if it was the chicken or the egg and what I guess I have learned, is that it's huge emotional distress that can trigger off the chemical imbalance in your mind.

As the next section details, participants made a strong distinction between the need for drugs to address a psychotic episode and the different need for supportive therapy for the individual person.

So what I found is that the tablets cover the chemical imbalance. It's the person, or the self that more than anything needs ... therapy or whatever you want to call it.
A distinction is made between what is appropriate during the acute phase and the long term perspective on recovery:

'In the long term, I think it's the person, the human being has to gain back and take that ground.

\section{Reclaiming sense of self}

There were many strong and clear statements that highlighted the insight that this set of consumers believe that drugs are only a minor part of the recovery experience. The first step in recovery was seen to be one of coming to a realisation that the person needs to begin to reclaim their sense of self which is seen as oppressed by a drug based mental health system. As one participant explains:

Recovery to me is about understanding, and getting familiar with the sense of self that I had given away to somebody else to define, so redefining that for myself. About a system that doesn't want to look at itself. In the name of wellness, or 'we are helping you', they [are] actually killing off the good in you.

Participants stated that it is important for health professionals in the mental health system to understand and support this point. The following statement is lengthy but included because it clearly outlines this significant point:

... and then the next seventeen years, I was in and out of hospital 15 times, because I didn't know what to do to get well, even though as I said I had [a university education]. I didn't know I had to do something. I thought it was medication etcetera ... But it wasn't. And it wasn't until my second last discharge from the hospital about six years ago, that I was referred to a private bulk billing consultant for external work. He said to me, 'Look the secret is, you've got to [do] something yourself'. But one of the major criteria I feel, and I feel even more strongly now, is that the system has to be encouraging towards that.

As another participant emphasises, 'The rest of the effort is required from one's self.'

The system needs to embrace and enthusiastically support the notion of recovery

A key idea for participants is the need for the psychiatric system to enthusiastically promote the idea of recovery. The conceptualisation of this idea was framed in the positive light of the way forward in assisting individuals to find their own way out of the oppression of mental illness. As one participant explains: 
[The system was] relatively negative - there was no encouraging aspect to the system, and I don't say this in a negative sense... but it's just the fact. Plus there wasn't anything within the system which would allow one to be enthused about ... any minute progression along that pathway to wellness.

It was noted that in such a system it is an easy option for consumers to just opt for the role of a patient with a mental illness.

I think I recognised in hindsight that I'd become addicted to the system because it seemed the only comfort zone. Once again this is where the system doesn't say, 'Look, you could find comfort in yourself, and we will encourage you to do so.'

One participant described their journey out of this role as:

I guess I made it - my own personal sort of transformation, whatever you want to call it, was really about letting the illness go. I began to relate to some people through my illness ... as a schizophrenic sort of thing. [Now changed] I didn't want to be known as 'the poor little schizophrenic; be nice because ill.'

\section{Risk management}

It was noted that as the system has a drug imperative, the avoidance of drug therapy confronts issues of risk management for mental health professionals. Participants were aware of the perception of danger:

You've got to think about people that really are dangerous to themselves. But as I have said, most of the problems you can treat without drugs, and be at home, and help people as an out-patient, or an inhome type situation.

One participant gave a detailed account of strategies which were worked out with the attending psychiatrist for dealing with issues of risk management.

He actually would ask me what I understood about things, and how I view it. He would say, 'I can see that maybe you're a fair bit sicker', and when he said that, that would mean that he had an obligation to lock me up at that point. I would [answer] that obligation, by saying, 'but naturally I will be at my own appointment next week, and despite how bad I look, there is no danger to myself or anyone else around me at this point.'

It was also noted that the risk of suppressing the trauma with drugs was as serious as the risk of going without medication. Participants indicated that the drug therapies are problematic in that they inhibit the person from entering the space where they can confront and deal with difficult emotions from past experiences. The concern is then that their whole life becomes one of risk management rather than recovery. As one participant succinctly summed up, 'The risk of the trauma is no better [than the risk of not taking drugs].'

\section{Recovery is better without drugs}

Many of the participants expressed strong statements about the importance of not including drugs as a strategy in recovery.

I don't think people really, really, need a pill a lot of the time. I think that medication is over used in a lot of psychiatric situations. I really do believe that.

The reasons for this varied and included the notion that even though it may feel bad without drugs this is preferable to the side effects. This was especially so when one of the significant side effects was memory loss which blocked the opportunity to work through past emotional events.

The bottom line was, I'm hourly drugged, and I couldn't work through my stuff. I had no real conscious idea of what was really the underlying problem with me.

The drugs are seen as blocking therapeutic opportunities of dealing with emotions:

[The drugs] absolutely push everything down everything - because really you are in an altered reality on medication. Absolutely. How can you be honest with anything?

It was noted the system does not presently allow for working through emotions, 'There's almost like no choice given to doing that' and there were calls for a change in the system:

Oh, it's going to have to change. There is a role for drugs, obviously. But I don't really think you need it for most people with mental illness.

\section{Discussion}

The findings highlight many negative aspects of the drug imperative within the Australian psychiatric system. Participants indicated that in their experience the mainstay of psychiatry is the administration of drugs which are given often without counselling, with little information and scant support to either the patient or their family. Individual resistance to drug therapy is seen as experimental and not easily tolerated by the mental health system; a system described as 
disempowering, offering scant therapeutic choices and not respecting individual difference. Other Australian research by Happell and associates (2004) back up these findings with similar insights indicating consumers of mental health services experience a general lack of education regarding both the reasons for prescribing specific medications and the side effects that may result from their use. Similarly, in the United States, Howard, El-Mallakh, Rayens \& Clark (2003) found that lack of education regarding medication was a major source of dissatisfaction for consumers.

A minority of participants do value the contribution that drug therapies can make to control the worst aspects of their mental illness. Also, drug treatment is seen as particularly important during a psychotic episode. However, a clear distinction is made between acute psychotic episodes and the long term nature of the recovery process. Even for those who are positive towards some drug use, this is seen as only part of the therapeutic solution. As shown in Table 1, there are major side effects from the drug therapies that are seen as distressing and outweighing the benefits for most participants. Consumers described being uninformed and unprepared to deal with the side effects of the drugs, which can make them feel worse and take away their sense of life and motivation. Castle (1997) refers to this consequence of medical therapy as 'debilitating psychosocial deficits and residual symptoms' and there is evidence of this phenomenon throughout the consumer-based mental health literature (e.g., Deegan, 1988; Fisher 2003; Happell et al., 2004; Tooth, Kalyansundaram, Glover \& Momenzadah, 2003). The findings echo the work of Mancini and associates (2005), who found a minority of participants in their study recorded psychiatric medications as key to their recovery, but almost half described the debilitating emotional, cognitive and physical side effects of their medications as 'barriers' to recovery. Similarly, a systematic study by the Scottish Association of Mental Health (SAMH) of 765 Scottish citizens diagnosed with mental disorders identifies many negative perceptions about the lack of discussion, lack of choice, disagreements, forced medications and unwanted side effects, while also acknowledging some symptom relief (SAMH, 2003). It is documented (Happell et al.,
2004) that consumers will alter their own medication dosages from those prescribed in response to unwanted side effects, usually without consultation because of communication difficulties with health professionals.

Thus, there is a consequent need on the part of the consumer to experiment with changing doses or types of drugs, or for many ceasing drugs altogether. However, such strategies are seen as going against standard practice and thus are resisted by many psychiatrists in the system. To explore therapeutic strategies other than drug treatments, the consumer needs to be highly motivated, mindful of the family consequences, and have the trust and support of a sympathetic psychiatrist. However, as Happell and associates (2004) document, there is a credibility gap in psychiatry, with consumers' opinions and requests for information frequently dismissed as symptomatic of mental illness rather than a legitimate claim for knowledge. The importance of the consumers' desire to be listened to, respected and involved in the decision making process is recorded elsewhere (Allen, Carpenter, Sheets et al., 2003; Happell et al., 2004).

The first step to recovery is seen to be one of coming to a realisation that the person needs to begin to reclaim their sense of self, which is described as oppressed by a drug based mental health system. The process is referred to by Davidson (2003) as living outside the illness and echoes Ramon and associates (2007) concept of 'self-agency' which is increasingly being recognised as a key element in recovery. Participants in the present study indicated that it could be easy to stay within the comfort zone of the clearly defined role of the psychiatric patient. The research by Young and Ensing (1999) refers to this as 'stuckness' and the challenge in relation to recovery is to overcome 'stuckness' through self-empowerment. The concern expressed by participants in the present study is that the mental health system neither informs patients that there are other constructive ways of dealing with their condition nor is it encouraging of efforts to find the 'self' through non-drug therapy. The system is described as maintaining the consumer in a disempowered position of control rather than supporting the idea of recovery. In the literature, this is referred to as the deficit model of living with mental illness 
that needs to be replaced by a 'strengths perspective' where the focus is on the person's capabilities rather than on a limited illness model (Ramon et al., 2007; Rapp, 1998; Saleebey, 1992). As Ramon and associates (2007, p. 111) explain:

Whereas the deficit model is based on an assumed overall, often permanent, vulnerability of the person expressed in difficulties to function and symptoms which contribute to malfunctioning, the strengths approach assumes that people with mental illness also have abilities and ambitions which motivate them to put these abilities to use.

Risk management was identified as a core concern in the present study. Consumers expressed awareness that there are issues of risk and danger from the health professionals' perspective; however, they also recorded a worry that concerns about risk management meant that consumers could not undertake therapeutic options that would ultimately lead to their recovery. The concern is then that the psychiatric management of a person with a diagnosis of mental illness becomes one of risk management rather than recovery. The drugs mask the real emotions and do not let the person deal with the emotional trauma contributing to their condition. It is noted that participants perceived the risk of suppressed trauma as greater than the risk of not taking drugs. The notion that risk taking is an integral factor in the recovery process is documented elsewhere (Ramon et al., 2007). As Deegan (1996) points out, the right to fail is an integral part of the new meaning given to the process of recovery. The core perspective informing any notion of risk taking is that interventions need to be person and not diagnosis oriented (O’Brien, Woods \& Palmer, 2001). As Connor (1999) points out, effective collaboration and the partnership between those who provide and receive services require trust and respect on both sides. However, although consumer participation in all levels of mental health service provision is now government policy in Australia, there is still considerable work to be done on the collaboration between mental health professionals and consumers (Connor, 1999).

Many of the consumers provided details that attest to recovery without drugs, which involves moving out of a drug regulated condition in the role of psychiatric patient, rediscovering the self, confronting emotional trauma, seeking information, and the support of a sympathetic psychiatrist (McGrath \& Jarrett, 2004). The support of family and friends is seen as essential as is the wisdom of others who have experienced similar life situations. There were calls for change within the system so that it can embrace practices that encourage recovery, empowerment and choice. The findings affirm the work of Tooth et al. (2003) who advocate the move away from viewing mental illness as a chronic unremitting disorder to a more optimistic position that incorporates the idea of recovery. As Ridgway (2001) emphasises, recovery is a process of active coping rather than passive adjustment, in which the individual needs to move away from withdrawal in the disempowered role of psychiatric patient to engage actively with life.

\section{Recommendations for practice}

Following are suggestions for improving the care offered by the mental health system gleaned from the participants' insights.

- Ensure patients and their families have full information on the side effects of drugs and ample opportunity to discuss the benefits and harms fully with health professionals looking after them.

- Understand that for individuals dealing with the challenge of a mental illness it is appropriate to explore different medications or the possibility of recovery without medication. Individuals need to be empowered and supported to explore such possibilities. Respecting individual difference and offering choice is the ethical guiding principles in this regard.

- The trust and respect of a sympathetic psychiatrist or other mental health professional is of crucial importance to consumers engaged in the difficult and challenging process of working out a personal recovery path.

- Some individuals will be highly motivated and seek appropriate help from sympathetic health professionals. Others will be overwhelmed and at risk of being 'stuck' in the system, conforming to the role of passive psychiatric patient. In essence it is important to respect individual differences and provide encouragement appropriately. 
- Be clear about consumers' perceptions about the difference in using medication for psychotic or acute episodes as compared to long term recovery.

- Importantly, be mindful that recovery is a very individual process and each person will need the time and support to find out what works best for them.

- The notion of risk management needs to incorporate the risks of control versus the risks of recovery. It is essential that the care offered by the mental health system is person, rather than diagnosis, oriented.

- The suitable paradigm for the mental health system is that of recovery, empowerment, active coping and choice, as opposed to management, control, chronic degenerative illness, and passive adjustment.

- Medications have a role, especially in relation to acute or psychotic episodes, but must be set in the context of the side effects associated with their use and the wealth of other factors that facilitate recovery.

\section{Conclusion}

It is the hope and expectation that these insights from a diverse range of people who have been successful in achieving recovery from a mental illness will go some way to shedding light on appropriate new directions for our twenty first century mental health care system. As one participant asks of the system of the future:

Really [try] to empower me in my own decision making, giving me the freedom and the room to grow.

\section{References}

Allen, M., Carpenter, D., Sheets, J., Miccio, S., \& Ross, R. (2003). What do consumers say they want and need during a psychiatric emergency? Journal of Psychiatric Practice, 9, 39-58.

Anderson, R., Oades, L., \& Caputi, P. (2003). The experience of recovery from schizophrenia: Towards an empirically validated stage model. Australia \& New Zealand Journal Psychiatry, 37(5), 586-601.

Anthony, W., Rogers, E., \& Farkas, M. (2003). Research on evidence-based practices: Future directions in an era of recovery. Community Mental Health Journal, 39, 101-14.

Australian Health Ministers (2003). National Mental Health Plan 2003-2008. Canberra: Australian Government.
Bishop, M. (2001). The recovery process and chronic illness and disability: Applications and implications. Journal Vocational Rehabilitation, 16(1), 47-52.

Castle, L. (1997). Beyond medication: What else does the patient with schizophrenia need to reintegrate into the community? Journal of Psychosocial Nursing and Mental Health Services, 35(9), 18-21, 41-2.

Connor, H. (1999). Collaboration or chaos: A consumer perspective. Australian and New Zealand Journal of Mental Health Nursing, 8(3), 79-85.

Davidson, L. (2003). Living Outside Mental Illness: Qualitative Studies of Recovery in Schizophrenia. New York: New York University Press.

Deegan, P. (1988). Recovery: The lived experience of rehabilitation. Psychosocial Rehabilitation Journal, 11, 11-19.

Deegan, P. (1996). Recovery as a journey of the heart. Psychiatric Rehabilitation Journal, 19, 91-7.

Deegan, P. (2003). Discovering recovery. Psychiatric Rehabilitation Journal, 26, 368-76.

Fisher, D. (2003). People are more important than pills in recovery from mental disorder. Journal of Humanistic Psychology, 43(2), 65-8.

Happell, B., Manias, E., \& Roper, C. (2004). Wanting to be heard: Mental health consumers' experiences of information about medication. International Journal of Mental Health Nursing, 13, 242-48.

Howard, P., El-Mallakh, P., Rayens, M.K., \& Clark, J. (2003). Consumer perspectives on quality of inpatient mental health services. Archives of Psychiatric Nursing, 17, 205-217.

Hutchinson, D., Skrinar, G., \& Cross, C. (1999). The role of improved physical fitness in rehabilition and recovery. Psychiatric Rehabilitation Journal, 22(4), 355-9.

Jacobson, N. \& Curtis, L. (2000). Recovery as policy in mental health services: Strategies emerging from states. Psychiatric Rehabilitation Journal 24(4), 33341.

Kirkpatrick, H., Landeen, J., Woodside, H., \& Byrne, A. (2001). How people with schizophrenia build their hope. Journal of Psychosocial Nursing and Mental Health Services, 39(1), 46-55.

Mancini, M.A., Hardiman, E.R., \& Lawson, H.A. (2005). Making sense of it all: Consumer providers' theories about factors facilitating and impeding recovery from psychiatric disabilities. Psychiatric Rehabilitation Journal, 29(1), 48-55.

McGrath, P. \& Jarrett, V. (2004). A slab over my head: Recovery insights from a consumer's perspective. International Journal of Psychosocial Rehabilitation, 9(1), 61-78. 
O’Brien, A., Woods, M., \& Palmer, C. (2001). The emancipation of nursing practice: Applying antipsychiatry to the therapeutic community. Australian and New Zealand Journal of Mental Health Nursing, 10(1), 3-9.

Pejlert, A., Asplund, K., \& Norberg, A. (1999). Towards recovery: Living in a home-like setting after the move from a hospital ward. Journal of Clinical Nursing, 8(6), 663-74.

Polit, D. \& Hungler, B. (1995). Nursing Research: Principles and Methods. Philadelphia: Lippincott.

Ramon, S., Healy, B., \& Renouf, N. (2007). Recovery from mental illness as an emergent concept and practice in Australia and the UK. International Journal of Social Psychiatry, 53(2), 108-22.

Rapp, C. (1998) The Strengths Model: Case Management with People Suffering from Severe and Persistent Mental Illness. New York: Oxford University Press.

Ridgway, M. (2001). Re-storying psychiatric disability: Learning from first person narrative accounts of recovery. Psychiatric Rehabilitation Journal, 24, 335-43.

Russlinova, Z. (1999). Providers' hope-inspiring competence as a factor optimizing psychiatric rehabilitation outcomes. Journal of Rehabilitation, 65(4), 50-7.

Saleebey, D. (Ed.) (1992). The Strength Approach in Social Work. New York: Longman.

Scottish Association for Mental Health, (SAMH) (2003). 'All You Need to Know?' Scottish Survey of People's Experience of Psychiatric drugs: Summary Report. Scottish Association for Mental Health. www.samh.org.uk/frontend/index.cfm?page $=280$

(Accessed $28^{\text {th }}$ August 2007).

Streubert, J. \& Carpenter, D. (1995). Qualitative Research in Nursing: Advancing the Humanistic Imperative. Philadelphia: Lippincott.

Tooth, B., Kalyansundaram, V., Glover, H., \& Momenzadah, S. (2003). Factors consumers identify as important to recovery from schizophrenia. Australasian Psychiatry, 11, S70-S77.

Tse, S. \& Walsh, A. (2001). How does work work for people with bipolar affective disorder? Occupational Therapy International, 8(3), 210-25.

Young, S. \& Ensing, D. (1999). Exploring recovery from the perspective of people with psychiatric disabilities. Psychiatric Rehabilitation Journal, 22(3), 219-31. 